Case Report

\title{
Three Patients Needing High Doses of Valproic Acid to Get Therapeutic Concentrations
}

\author{
James Jackson, ${ }^{1}$ Betsy McCollum, ${ }^{2}$ Judy Ognibene, ${ }^{3}$ Francisco J. Diaz, ${ }^{4}$ and Jose de Leon ${ }^{1,5}$ \\ ${ }^{1}$ Department of Psychiatry, College of Medicine, University of Kentucky, Lexington, KY 40509, USA \\ ${ }^{2}$ Pharmacy, Eastern State Hospital, Lexington, KY 40511, USA \\ ${ }^{3}$ Apalachee, Inc., Eastside Psychiatric Hospital, Tallahassee, FL 32308, USA \\ ${ }^{4}$ Department of Biostatistics, The University of Kansas Medical Center, Kansas City, KS 66160, USA \\ ${ }^{5}$ University of Kentucky Mental Health Research Center, Eastern State Hospital, Lexington, KY 40511, USA \\ Correspondence should be addressed to Jose de Leon; jdeleon@uky.edu
}

Received 28 February 2015; Accepted 8 April 2015

Academic Editor: Liliana Dell'Osso

Copyright (c) 2015 James Jackson et al. This is an open access article distributed under the Creative Commons Attribution License, which permits unrestricted use, distribution, and reproduction in any medium, provided the original work is properly cited.

\begin{abstract}
Valproic acid (VPA) can autoinduce its own metabolism. Cases requiring VPA doses $>4000 \mathrm{mg} /$ day to obtain therapeutic plasma concentrations, such as these 3 cases, have never been published. Case 1 received VPA for seizures and schizophrenia and had $>50$ VPA concentrations in 4 years. A high dose of $5,250 \mathrm{mg} /$ day of VPA concentrate was prescribed for years but this dose led to an intoxication when switched to the enterocoated divalproex sodium formulation, requiring a normal dose of $2000 \mathrm{mg} / \mathrm{day}$. VPA metabolic capacity was significantly higher $(t=-9.6 ; \mathrm{df}=6.3, p<0.001)$ during the VPA concentrate therapy, possibly due to autoinduction in that formulation. Case 2 had VPA for schizoaffective psychosis with 10 VPA concentrations during an 8-week admission. To maintain a VPA level $\geq 50 \mu \mathrm{g} / \mathrm{mL}$, VPA doses increased from 1500 to $4000 \mathrm{mg} /$ day. Case 3 had tuberous sclerosis and epilepsy and was followed up for $>4$ years with 137 VPA concentrations. To maintain VPA concentrations $\geq 50 \mu \mathrm{g} / \mathrm{mL}$, VPA doses increased from 3,375 to 10,500 mg/day. In Cases 2 and 3, the duration of admission and the VPA dose were strongly correlated $(r$ around $0.90 ; p<0.001$ ) with almost no change after controlling for VPA concentrations, indicating progressive autoinduction that increased with time.
\end{abstract}

\section{Introduction}

Valproic acid (VPA) is a classic antiepileptic drug (AED) and has been a major pharmaceutical tool in the management of a range of psychiatric and neurological diseases since the 1960s [1]. VPA is currently approved in the US for the treatment of several types of epilepsy, bipolar disorder, and migraine prophylaxis. The maximum recommended doses for epilepsy or bipolar disorder are $60 \mathrm{mg} / \mathrm{kg} /$ day [2]. It is rare to see patients taking $>4000 \mathrm{mg} /$ day. Moreover, therapeutic drug monitoring (TDM) is frequently used to establish and track VPA doses. Neurologists frequently use a therapeutic range of $50-100 \mu \mathrm{g} / \mathrm{mL}$ for epilepsy [3]. The therapeutic range in bipolar disorder is not very well established but some reviews recommend up to $125 \mu \mathrm{g} / \mathrm{mL}$ for mania [2].

In spite of decades of use, VPA metabolism is not completely understood [3-8]. VPA primarily undergoes hepatic metabolism, while $<5 \%$ is eliminated and unchanged in the urine. The major mechanisms of hepatic metabolism are the uridine diphosphate glucuronosyltransferases (UGTs; 40\%) and $\beta$-oxidation as a fatty acid $(30 \%)$, with the cytochrome P450 (CYP; including CYP2C9, CYP2C19, and CYP2A6) as a minor component in the metabolic process. At low doses, $\beta$ oxidation may be the most important pathway, while at therapeutic doses glucuronidation may be more important [3-8]. Many UGTs appear to be involved in valproate glucuronidation including UGT1A3, UGT1A4, UGT1A6, UGT1A9, and UGT2B7, along with the primarily intestinal UGT1A8 and UGT1A10 [9].

Regarding the potential of causing drug-drug interactions (DDIs), VPA was traditionally considered to be a moderate inhibitor of several enzymes including CYP2C9, epoxide hydroxylase, several UGTs, and the N-glucosidation pathway of phenobarbital [4]. First, rat studies suggested that VPA 
may autoinduce its own glucuronidation [10]. The first clinical suggestions that VPA may autoinduce its own metabolism were from studies focused on felbamate [11] and lamotrigine [12]. More recent studies have been able to demonstrate that VPA induces (1) its own metabolism by inducing $\beta$-oxidation (prospective study) [13]; (2) CYP3A4 and P-gp gene expression (in vitro study) [14]; (3) possible UGT1A1 in a patient taking irinotecan (which has an active metabolite, SN-38, metabolized by UGT1A1) [15]; (4) aripiprazole metabolism to a mild degree (prospective study) [16]; (5) olanzapine metabolism (case series [17], TDM [18], a statistical model of TDM-DDI studies [19], and a prospective DDI study) [20]; (6) clozapine metabolism (case series [21, 22], a prospective case report [23], and statistical models of TDM-DDI studies $[24,25])$; and (7) vitamin D metabolism in an in vitro study [26]. In summary, VPA may be like other AEDs, such as oxcarbazepine or topiramate, and act as a mild inducer for some metabolic enzymes and behave as a clinically relevant inhibitor of other metabolic enzymes.

The following 3 cases, accumulated by the senior author in the last 20 years of his clinical practice, describe 3 patients needing high doses of VPA to reach and maintain therapeutic concentrations $\geq 50 \mu \mathrm{g} / \mathrm{mL}$. Recent advances in pharmacokinetic knowledge have allowed us to offer a hypothesis about these patients' needs for such high VPA doses to reach therapeutic concentrations. On February 19, 2015, we conducted a PubMed search using the words "valproic acid and (high dose or high dosage)" limiting them to title or abstract, human participants, and case reports, which provided 33 articles. None of these 33 articles described the therapeutic use of VPA doses $>4000 \mathrm{mg} /$ day. We decided to publish these cases because it is very likely that other clinicians have seen similar patients but did not write about them.

\section{Methods}

2.1. Clinical Setting. The senior author collected these 3 cases during the last 20 years while working as a clinician and/or consultant in the public mental health system in Kentucky, USA. During 8 of those years, he managed a 30-bed treatment-refractory unit for psychotic patients in a state hospital with approximately 1600 admissions/year. He acquired Cases 1 and 3 in that setting. For 14 years he has also acted as a consultant for difficult cases, including those needing high doses of psychiatric medications in 4 state hospitals for severe mentally ill patients, 4 hospitals for adults with intellectual disabilities, and 2 nursing homes. Case 2 was collected as a consultant for another psychiatrist (third author). In the senior author's experience, VPA is probably the most frequently prescribed psychotropic drug in the public mental health system facilities of Kentucky, with more than 1000 patients every year treated with VPA at state facilities. The 3 patients in this paper participated in pharmacogenetic studies after written informed consent forms were signed by them and/or their guardians.

2.2. TDM. These 3 cases contain TDM information that was collected for clinical purposes many years ago. The VPA TDM was done by immunoassay in the same psychiatric hospital using the same clinical laboratory at the hospital; levels were taken as trough concentrations (early AM before taking medications) and after reaching steady state. The VPA concentrations were measured in $\mu \mathrm{g} / \mathrm{mL}$, which is the same as $\mathrm{mg} / \mathrm{L}$.

In the last 10 years, the senior author has increasingly used the pharmacological concept of concentration-to-dose ratio (C/D ratio) to study TDM in order to personalize the prescription of psychiatric medications in psychopharmacology. The $\mathrm{C} / \mathrm{D}$ ratio is a measure of the ability to eliminate the drug and is influenced by genetic, personal, and environmental factors. Inducers decrease the $\mathrm{C} / \mathrm{D}$ ratio and inhibitors increase the $\mathrm{C} / \mathrm{D}$ ratio. In comparing individuals taking the same drug, a very low $\mathrm{C} / \mathrm{D}$ ratio indicates an individual with very fast metabolism, while a very high $\mathrm{C} / \mathrm{D}$ ratio indicates one with very slow metabolism. Each drug is different and unique and has its own normal ranges for $\mathrm{C} / \mathrm{D}$ ratios determined by its own bioavailability and elimination from the body.

The senior author has used the C/D ratio to interpret TDM of clobazam [27], clozapine, and risperidone [28]. These 3 drugs, like the majority of drugs used in neuropsychopharmacology, follow linear kinetics. A linear relationship exists between typical doses and plasma concentrations. This means that the relationship between concentration and dose is stable; it does not change with different doses and concentrations, and the drug $\mathrm{C} / \mathrm{D}$ ratio is constant in the same patient as long as there are no changes in environmental or personal variables.

VPA TDM, unfortunately, is a little more complicated since it does not follow linear kinetics. The relationship between VPA dose and total concentration is nonlinear; the concentration does not increase proportionally with the dose but increases to a lesser extent due to saturable plasmaprotein binding [29]. As the VPA C/D ratio is not constant and changes with different doses and concentrations, one needs to further interpret VPA C/D ratios in the context of a set of concentrations or set of doses.

The senior author has started using VPA C/D ratios in his teaching and clinical practice in the last 3 years and is not aware of any published article using them. Therefore, as the reader may not be familiar with the use of $\mathrm{C} / \mathrm{D}$ ratios for valproate VPA, this section provides a short introduction. Based on experience as a lecturer, the senior author has figured out that VPA C/D ratios have values too low to be easily understood by physicians, who do not tend to be particularly strong in mathematics. To more easily understand the VPA C/D values, they are also presented with a value obtained by multiplying by 1000 . To understand this, let us assume that a VPA dose of $2000 \mathrm{mg} /$ day provides a total VPA concentration of $100 \mu \mathrm{g} / \mathrm{mL}$. Therefore the C/D ratio in this patient is $100 / 2000$ or 0.05 . The C/D ratio multiplied by 1000 would be 50 , an easier number to grasp.

Next, we can use a published case of VPA toxicity [29] to explain the interpretation of VPA C/D ratio for clinical use. To simplify, Table 1 presents only the VPA data including $\mathrm{C} / \mathrm{D}$ ratios using total VPA concentrations. This patient has relatively narrow variations, with a $\mathrm{C} / \mathrm{D}$ ratio multiplied by 1000 ranging between 112 and 132 (Table 1). These values are 
TABLE 1: Explaining VPA C/D ratio use with VPA concentrations from a published case [29].

\begin{tabular}{lcccc}
\hline Formulation & VPA dose $(\mathrm{mg} /$ day $)$ & Concentration $(\mu \mathrm{g} / \mathrm{mL})$ & C/D ratio & C/D ratio $\times 1000$ \\
\hline ECDVNa & 1000 & 112 & 0.112 & 112 \\
ECDVNa & 750 & 87 & 0.116 & 116 \\
ECDVNa & 500 & 66 & 0.132 & 132 \\
ECDVNa & 500 & 64 & 0.128 & 128 \\
\hline
\end{tabular}

C/D: concentration-to-dose; ECDVNa: divalproex sodium enterocoated; VPA: valproic acid.

normal in the experience of the senior author. Moreover, these values follow the usual pattern of VPA C/D ratios. In low doses, in this case $500 \mathrm{mg} / \mathrm{day}$, the $\mathrm{C} / \mathrm{D}$ ratio multiplied by 1000 ranged from 128 to 132 . In high doses, in this case $1000 \mathrm{mg} / \mathrm{day}$, the $\mathrm{C} / \mathrm{D}$ ratio multiplied by 1000 was 112 , indicating a faster metabolism at $1000 \mathrm{mg} /$ day than at the $500 \mathrm{mg} /$ day dose. At higher VPA doses, plasma proteins such as albumin are saturated by VPA and the percentage of free (unbound) VPA concentration increases. Since free VPA is the entity that is metabolized, the higher the percentage of free concentration is, the faster the VPA is metabolized. In the experience of the senior author, approximately $90 \%$ of VPA on average is carried by plasmatic proteins and $10 \%$ is free at standard therapeutic concentrations. With higher concentrations, the relative concentrations of free VPA increase (e.g., 85\% bound and 15\% free), and with low concentrations it decreases (e.g., 95\% bound and 5\% free). These percentages of free VPA concentration are also influenced by (1) the plasma concentration of albumin and other plasmatic proteins, (2) plasma concentrations of some endogenous compounds that may bind to the proteins (e.g., bilirubin), and (3) the presence of other drugs (e.g., aspirin), which may also compete for plasmatic protein binding [29].

Other examples of VPA C/D ratio are calculated using published data [30, 31]. A case [30] of a possible VPA adverse drug reaction $(\mathrm{ADR})$ occurred in a patient who had a VPA concentration $78 \mu \mathrm{g} / \mathrm{mL}$ at a dose of $1500 \mathrm{mg} /$ day (C/D ratio $=0.520$ calculated by 78/1500). The VPA C/D ratio multiplied by 1000 was 520. In a study of VPA TDM [31], 14 females had an average VPA concentration of $76 \mu \mathrm{g} / \mathrm{mL}$ with an average maintenance dose of $629 \mathrm{mg} /$ day $(\mathrm{C} / \mathrm{D}$ ratio $=0.121$ calculated by 76/629) and a VPA C/D ratio multiplied by 1000 of 121 . In the same study, 23 males had an average VPA concentration of $70 \mu \mathrm{g} / \mathrm{mL}$ with an average maintenance dose of $617 \mathrm{mg} /$ day $(\mathrm{C} / \mathrm{D}$ ratio $=0.113$ calculated by $70 / 617)$ with a VPA C/D ratio multiplied by 1000 of 113 .

These 3 cases needing VPA doses $>4000 \mathrm{mg}$ /day to obtain VPA therapeutic concentrations had very low mean C/D ratios multiplied by 1000: in the 20s or lower, possibly due to VPA autoinduction.

2.3. Scale. For this paper, we have completed the Drug Interaction Probability Scale (DIPS) [32] for each of the 3 cases.

2.4. Statistics. Available data for each of the 3 cases was dictated by clinical care; many years later we tried to use statistical techniques to accommodate the available data and the questions asked in each case. The Statistical Package for the Social Sciences (SPSS 22) was used to analyze the data. In Case 1 an independent sample $t$-test compared mean VPA C/D ratios from the two VPA formulations, one probably accompanied with autoinduction and the other not. Pearson correlations between VPA dose and day of admission were used in Cases 2 and 3 to demonstrate that higher doses were needed to keep the VPA concentrations therapeutic over time, which is consistent with a pattern of autoinduction. Partial correlations were used to demonstrate that VPA concentrations did not explain the correlation between VPA dose and day of admission.

\section{Case Presentations}

3.1. Case 1. A Caucasian male was followed up for more than 4 years between the ages of 30 and 34 years. His initial weight was $85 \mathrm{Kg}$. He smoked 10 cigarettes per day. His psychosis started when he was 12 years old and had been refractory to treatment for many years at the time of admission. The patient had three seizures of unknown origin in the 3 months before coming under the care of the senior author. Academic neurologists had examined him at least twice. All tests, including a CT scan of the head, were negative. After a careful review of all records, it was the impression of the senior author that at least 1 or 2 of the 3 seizures might have been associated with rapid withdrawal of high doses of benzodiazepines, particularly temazepam, used as PRNs. He arrived at the unit with four antiepileptic medications in his regimen: carbamazepine, phenytoin, diazepam, and VPA. These medications had been progressively added by the neurology consultants. The blood levels of all four of these medications were subtherapeutic. After several months the senior author was able to change the regimen to VPA only, without the patient having any seizures during his long admission. The VPA treatment is described in detail in Table 2. To avoid too much irrelevant information, day 164 of admission was selected as day 1 to describe the time-course of VPA treatment. The senior author was surprised that this patient needed $5250 \mathrm{mg} /$ day of VPA concentrate to get therapeutic VPA concentrations. After more than 3.5 years of admission, the patient was finally stabilized on clozapine at $700 \mathrm{mg}$ /day, his psychotic symptoms had greatly improved, and he was getting ready to be discharged. However, he then began to complain about the taste of the VPA concentrate in his mouth. With the assumption of bioequivalent formulations and dosing, the patient was switched to divalproex sodium at a total daily dose of $5250 \mathrm{mg} /$ day. This led to an unexpected VPA intoxication despite the absence of any other medication changes. 
TABLE 2: VPA C/D ratio in Case 1.

\begin{tabular}{|c|c|c|c|c|}
\hline Day & VPA dose (mg/day) & Concentration $(\mu \mathrm{g} / \mathrm{mL})$ & $\mathrm{C} / \mathrm{D}$ ratio & $\mathrm{C} / \mathrm{D}$ ratio $\times 1000$ \\
\hline \multicolumn{5}{|c|}{ Valproic acid concentrate $\left(\mathrm{C} / \mathrm{D}\right.$ ratio $\times 1000:$ mean $\pm S D=15^{1} \pm 2.6$, range $\left.=10-21\right)$} \\
\hline $7^{3}$ & 5250 & 54 & 0.010 & 10 \\
\hline $14^{4}$ & 5250 & 68 & 0.013 & 13 \\
\hline $21^{5}$ & 5250 & 68 & 0.013 & 13 \\
\hline $29^{5}$ & 5250 & 76 & 0.014 & 14 \\
\hline $70^{5}$ & 5250 & 59 & 0.011 & 11 \\
\hline $98^{6}$ & 5250 & 66 & 0.013 & 13 \\
\hline $119^{6}$ & 5250 & 85 & 0.016 & 16 \\
\hline $126^{6}$ & 5250 & 61 & 0.012 & 12 \\
\hline $140^{6}$ & 5250 & 75 & 0.014 & 14 \\
\hline $175^{6}$ & 5250 & 79 & 0.015 & 15 \\
\hline $188^{6}$ & 5250 & 64 & 0.012 & 12 \\
\hline $202^{7}$ & 5250 & 64 & 0.012 & 12 \\
\hline $238^{8}$ & 5250 & 88 & 0.017 & 17 \\
\hline $252^{8}$ & 5250 & 110 & 0.021 & 21 \\
\hline $260^{9}$ & 5250 & 86 & 0.016 & 16 \\
\hline $280^{9}$ & 5250 & 92 & 0.018 & 18 \\
\hline $287^{9}$ & 5250 & 87 & 0.017 & 17 \\
\hline $301^{10}$ & 5250 & 87 & 0.017 & 17 \\
\hline $319^{10}$ & 5250 & 92 & 0.018 & 18 \\
\hline $350^{10}$ & 5250 & 99 & 0.019 & 19 \\
\hline $378^{11}$ & 5250 & 85 & 0.016 & 16 \\
\hline $420^{12}$ & 5250 & 91 & 0.017 & 17 \\
\hline $427^{12}$ & 5250 & 97 & 0.018 & 18 \\
\hline $434^{12}$ & 5250 & 87 & 0.017 & 17 \\
\hline $470^{12}$ & 5250 & 87 & 0.017 & 17 \\
\hline $498^{13}$ & 5250 & 90 & 0.017 & 17 \\
\hline $552^{13}$ & 5250 & 95 & 0.018 & 18 \\
\hline $582^{13}$ & 5250 & 81 & 0.015 & 15 \\
\hline $609^{13}$ & 5250 & 88 & 0.017 & 17 \\
\hline $637^{7}$ & 5250 & 80 & 0.015 & 15 \\
\hline $928^{14}$ & 5250 & 111 & 0.021 & 21 \\
\hline $945^{15}$ & 5250 & 93 & 0.018 & 18 \\
\hline $978^{16}$ & 5250 & 78 & 0.015 & 15 \\
\hline $998^{17}$ & 5250 & 67 & 0.013 & 13 \\
\hline $1026^{18}$ & 5250 & 67 & 0.013 & 13 \\
\hline $1054^{19}$ & 5250 & 66 & 0.013 & 13 \\
\hline $1082^{19}$ & 5250 & 71 & 0.014 & 14 \\
\hline $1110^{19}$ & 5250 & 63 & 0.012 & 12 \\
\hline $1145^{20}$ & 5250 & 69 & 0.013 & 13 \\
\hline $1166^{21}$ & 5250 & 93 & 0.018 & 18 \\
\hline $1202^{22}$ & 5250 & 89 & 0.017 & 17 \\
\hline $1208^{23}$ & 5250 & 75 & 0.014 & 14 \\
\hline $1236^{24}$ & 5250 & 88 & 0.017 & 17 \\
\hline $1251^{25}$ & 5250 & 87 & 0.017 & 17 \\
\hline \multicolumn{5}{|c|}{ EC divalproex sodium $\left(C / D\right.$ ratio $\times 1000:$ mean $\pm S D=39^{1} \pm 6.3$, range $\left.=28-48\right)$} \\
\hline $1306^{25}$ & 5250 & $145^{2}$ & 0.028 & 28 \\
\hline $1320^{25}$ & 3750 & 135 & 0.036 & 36 \\
\hline $1334^{25}$ & 3000 & 127 & 0.042 & 42 \\
\hline $1373^{25}$ & 2500 & 120 & 0.048 & 48 \\
\hline
\end{tabular}


TABLE 2: Continued.

\begin{tabular}{lcccc}
\hline Day & VPA dose $(\mathrm{mg} /$ day $)$ & Concentration $(\mu \mathrm{g} / \mathrm{mL})$ & C/D ratio & C/D ratio $\times 1000$ \\
\hline $1348^{25}$ & 2000 & 73 & 0.037 & 37 \\
$1362^{25}$ & 2000 & 82 & 0.041 & 41 \\
$1376^{25}$ & 2000 & 78 & 0.039 & 39 \\
\hline
\end{tabular}

C/D: concentration-to-dose; EC: enterocoated; VPA: valproic acid.

${ }^{1}$ According to an independent $t$-test calculated with equal variance not assumed, there was significant difference $(t=-9.6 ; \mathrm{df}=6.3, p<0.001)$ between these two means, 15 in VPA concentrate and 39 in divalproex sodium.

${ }^{2}$ This VPA concentration was measured 4 weeks after switching from VPA concentrate to divalproex sodium. With a high VPA concentration at that time, the patient showed increased drowsiness.

${ }^{3}$ Other scheduled oral medications included benztropine $3 \mathrm{mg} /$ day, gemfibrozil $1200 \mathrm{mg} /$ day, propranolol $80 \mathrm{mg} /$ day, and quetiapine $700 \mathrm{mg} / \mathrm{day}$.

${ }^{4}$ Other scheduled oral medications included benztropine $3 \mathrm{mg} /$ day, gemfibrozil $1200 \mathrm{mg} /$ day, olanzapine $5 \mathrm{mg} /$ day, propranolol $80 \mathrm{mg} / \mathrm{day}$, and quetiapine $500 \mathrm{mg} /$ day.

${ }^{5}$ Other scheduled oral medications included benztropine $3 \mathrm{mg} / \mathrm{day}$, gemfibrozil $1200 \mathrm{mg} / \mathrm{day}$, olanzapine $5 \mathrm{mg} / \mathrm{day}$, and propranolol $80 \mathrm{mg} / \mathrm{day}$.

${ }^{6}$ Other scheduled oral medications included benztropine $4 \mathrm{mg}$ /day, gemfibrozil $1200 \mathrm{mg} /$ day, olanzapine $5 \mathrm{mg} /$ day, and propranolol $80 \mathrm{mg} / \mathrm{day}$.

${ }^{7}$ Other scheduled oral medications included benztropine $4 \mathrm{mg}$ /day, gemfibrozil $1200 \mathrm{mg} /$ day, olanzapine $5 \mathrm{mg} /$ day, and propranolol $60 \mathrm{mg} / \mathrm{day}$.

${ }^{8}$ Other scheduled oral medications included benztropine $4 \mathrm{mg} / \mathrm{day}$, gemfibrozil $1200 \mathrm{mg} / \mathrm{day}$, olanzapine $2.5 \mathrm{mg} /$ day, and propranolol $30 \mathrm{mg} / \mathrm{day}$.

${ }^{9}$ Other scheduled oral medications included benztropine $4 \mathrm{mg} / \mathrm{day}$, gemfibrozil $1200 \mathrm{mg} / \mathrm{day}$, olanzapine $2.5 \mathrm{mg} /$ day, and propranolol $40 \mathrm{mg} / \mathrm{day}$.

${ }^{10}$ Other scheduled oral medications included benztropine $4 \mathrm{mg} /$ day, gemfibrozil $1200 \mathrm{mg} /$ day, olanzapine $2.5 \mathrm{mg} /$ day, and propranolol $60 \mathrm{mg} / \mathrm{day}$.

${ }^{11}$ Other scheduled oral medications included benztropine $4 \mathrm{mg} /$ day, gemfibrozil $1200 \mathrm{mg} /$ day, olanzapine $2.5 \mathrm{mg} /$ day, and propranolol $120 \mathrm{mg} / \mathrm{day}$.

${ }^{12}$ Other scheduled oral medications included benztropine $4 \mathrm{mg} /$ day, clonidine $0.1 \mathrm{mg} / \mathrm{day}$, gemfibrozil $1200 \mathrm{mg} /$ day, olanzapine $2.5 \mathrm{mg} / \mathrm{day}$, and propranolol $60 \mathrm{mg} / \mathrm{day}$.

${ }^{13}$ Other scheduled oral medications included benztropine $4 \mathrm{mg} / \mathrm{day}$, gemfibrozil $1200 \mathrm{mg} / \mathrm{day}$, olanzapine $2.5 \mathrm{mg} /$ day, and propranolol $60 \mathrm{mg} / \mathrm{day}$.

${ }^{14}$ Other scheduled oral medications included benztropine $4 \mathrm{mg} /$ day, clozapine $25 \mathrm{mg} /$ day, gemfibrozil $1200 \mathrm{mg} /$ day, olanzapine $10 \mathrm{mg} / \mathrm{day}$, and propranolol $80 \mathrm{mg} / \mathrm{day}$.

${ }^{15}$ Other scheduled oral medications included benztropine $4 \mathrm{mg} /$ day, clozapine $300 \mathrm{mg} /$ day, gemfibrozil $1200 \mathrm{mg} /$ day, olanzapine $10 \mathrm{mg} / \mathrm{day}$, and propranolol $80 \mathrm{mg} / \mathrm{day}$.

${ }^{16}$ Other scheduled oral medications included benztropine $4 \mathrm{mg} /$ day, clozapine $600 \mathrm{mg} /$ day, gemfibrozil $1200 \mathrm{mg} /$ day, olanzapine $10 \mathrm{mg} / \mathrm{day}$, and propranolol $80 \mathrm{mg} /$ day.

${ }^{17}$ Other scheduled oral medications included benztropine $4 \mathrm{mg} /$ day, clozapine $400 \mathrm{mg} / \mathrm{day}$, gemfibrozil $1200 \mathrm{mg} / \mathrm{day}$, olanzapine $10 \mathrm{mg} / \mathrm{day}$, and propranolol $80 \mathrm{mg} /$ day.

${ }^{18}$ Other scheduled oral medications included benztropine $4 \mathrm{mg} /$ day, clozapine $700 \mathrm{mg} / \mathrm{day}$, gemfibrozil $1200 \mathrm{mg} / \mathrm{day}$, olanzapine $10 \mathrm{mg} / \mathrm{day}$, and propranolol $80 \mathrm{mg} / \mathrm{day}$.

${ }^{19}$ Other scheduled oral medications included benztropine $4 \mathrm{mg} /$ day, clozapine $800 \mathrm{mg} /$ day, gemfibrozil $1200 \mathrm{mg} /$ day, and propranolol $80 \mathrm{mg} / \mathrm{day}$.

${ }^{20}$ Other scheduled oral medications included atorvastatin $10 \mathrm{mg} /$ day, benztropine $4 \mathrm{mg} /$ day, clozapine $800 \mathrm{mg} /$ day, and propranolol $80 \mathrm{mg} /$ day.

${ }^{21}$ Other scheduled oral medications included atorvastatin $20 \mathrm{mg} /$ day, benztropine $4 \mathrm{mg}$ /day, clozapine $800 \mathrm{mg} /$ day, and propranolol $80 \mathrm{mg} / \mathrm{day}$.

${ }^{22}$ Other scheduled oral medications included atorvastatin $20 \mathrm{mg} /$ day, clozapine $700 \mathrm{mg} / \mathrm{day}$, docusate $250 \mathrm{mg} /$ day, and propranolol $80 \mathrm{mg} / \mathrm{day}$.

${ }^{23}$ Other scheduled oral medications included atorvastatin $20 \mathrm{mg} /$ day, benztropine $0.5 \mathrm{mg} /$ day, clozapine $700 \mathrm{mg} /$ day, docusate $250 \mathrm{mg} / \mathrm{day}$, and propranolol $80 \mathrm{mg} /$ day.

${ }^{24}$ Other scheduled oral medications included atorvastatin $20 \mathrm{mg} /$ day, benztropine $1 \mathrm{mg} /$ day, clozapine $600 \mathrm{mg} /$ day, docusate $250 \mathrm{mg} /$ day, and propranolol $80 \mathrm{mg} /$ day.

${ }^{25}$ Other scheduled oral medications included atorvastatin $20 \mathrm{mg}$ /day, benztropine $1 \mathrm{mg} /$ day, clozapine $700 \mathrm{mg} /$ day, docusate $250 \mathrm{mg} /$ day, and propranolol $80 \mathrm{mg} /$ day.

This unexpected outcome left the senior author perplexed and led him to a brief preliminary publication on VPA concentrations during the last 3 months of admission [33], despite having no pharmacological explanation at that time. Table 2 presents a comprehensive list of the VPA concentrations during most of 4 years, as well as the corresponding VPA C/D ratios. While the patient was being maintained on $5250 \mathrm{mg} /$ day of VPA concentrate for many years, the VPA $\mathrm{C} / \mathrm{D}$ ratio multiplied by 1000 yielded values ranging from 10 to 21 with a mean of 15 . Divalproex sodium treatment yielded VPA C/D values which, multiplied by 1000 , ranged from 28 to 48 , with a mean of 39 . The means of 19 and 39 were found to be significantly different (Table 2 , footnote 1 ), indicating that the patient's ability to metabolize VPA was significantly higher on VPA concentrate than on divalproex sodium.

It is likely that this case presentation reflects the result of VPA autoinduction only present during VPA concentrate versus no autoinduction during divalproex sodium use. The DIPS score was 6 , which corresponds to a probable drug interaction in this case (scored as 1 point each for questions $2,3,4,7,8$, and 9 ).

3.2. Case 2. Patient 2 was a 66-year-old Caucasian male nonsmoker with a 26-year history of bipolar disorder and a history of polysubstance abuse (alcohol and cocaine). His initial weight was $90 \mathrm{Kg}$. He had 7 prior psychiatric admissions. On presentation the patient met the criteria for hypomanic episode with psychotic features. He had a positive viral panel for hepatitis $\mathrm{C}$ and his Hep C RNA PCR was positive, but his liver function profile and metabolic panel were unremarkable. Sublingual asenapine $20 \mathrm{mg} /$ day, one of his outpatient medications, was restarted by the third author on hospital day 2 in addition to VPA $1000 \mathrm{mg} /$ day, which the patient had not received as an outpatient. Other medications are described in Table 3. The patient did not experience any signs of VPA toxicity as the dose was increased during his admission. However, he remained hypomanic and continued to display rapid, pressured speech and flight of 
TABle 3: VPA C/D ratio in Case 2.

\begin{tabular}{|c|c|c|c|c|c|}
\hline Day $^{1}$ & Formulation & VPA dose ${ }^{1}$ (mg/day) & Concentration $(\mu \mathrm{g} / \mathrm{mL})$ & $\mathrm{C} / \mathrm{D}$ ratio & $\mathrm{C} / \mathrm{D}$ ratio $\times 1000^{2}$ \\
\hline \multicolumn{6}{|c|}{ All $10 \mathrm{VPA}$ concentrations $(\mathrm{C} / \mathrm{D}$ ratio $\times 1000:$ mean $\pm \mathrm{SD}=25 \pm 5.6$, range $=17-33)$} \\
\hline \multicolumn{6}{|c|}{8 therapeutic $^{2}$ VPA concentrations $(\mathrm{C} / \mathrm{D}$ ratio $\times 1000:$ mean $\pm \mathrm{SD}=24 \pm 5.6$, range $=17-33)$} \\
\hline $5^{3}$ & ECDVNa & 1500 & 39 & 0.026 & 26 \\
\hline $8^{3}$ & ECDVNa & 1500 & 49 & 0.033 & 33 \\
\hline $14^{4}$ & ECDVNa & 2500 & 61 & 0.024 & 24 \\
\hline $20^{5}$ & ECDVNa & 2500 & 75 & 0.030 & 30 \\
\hline $23^{6}$ & ECDVNa & 2500 & 82 & 0.033 & 33 \\
\hline $29^{7}$ & ECDVNa & 3000 & 77 & 0.026 & 26 \\
\hline $36^{7}$ & Concentrate & 3500 & 72 & 0.020 & 20 \\
\hline $41^{7}$ & Concentrate & 3500 & 78 & 0.022 & 22 \\
\hline $48^{8}$ & Concentrate & 4000 & 73 & 0.018 & 18 \\
\hline $55^{9}$ & ECDVNa & 4000 & 67 & 0.017 & 17 \\
\hline
\end{tabular}

C/D: concentration-to-dose; ECDVNa: enterocoated divalproex sodium; VPA: valproic acid.

${ }^{1}$ The Pearson correlation between day of admission and VPA dose was $r=0.97(p<0.001)$; VPA dose remained significant in a partial correlation while controlling for VPA concentration: $r=0.96(p<0.001)$. This is compatible with a progressive autoinduction indicating, at least with dose range, that it was necessary to increase the dose as the duration lengthened.

${ }^{2} 50-125 \mu \mathrm{g} / \mathrm{mL}$ concentrations are considered therapeutic concentrations. As this patient has 2 nontherapeutic concentrations, it would be better to compare a priori with other patients using only the VPA therapeutic concentrations. In reality, eliminating the first 2 VPA concentrations, which were subtherapeutic, made almost no difference.

${ }^{3}$ Other scheduled oral medications included asenapine $10 \mathrm{mg} / \mathrm{day}$, naproxen $1000 \mathrm{mg} / \mathrm{day}$, omeprazole $20 \mathrm{mg} / \mathrm{day}$, trimethoprim/sulfamethoxazole $1600 / 320 \mathrm{mg} /$ day (for skin breakdown over swollen lower extremities), and trazodone $100 \mathrm{mg} / \mathrm{day}$.

${ }^{4}$ Other scheduled oral medications included asenapine $15 \mathrm{mg} /$ day, gabapentin $900 \mathrm{mg} / \mathrm{day}$, lisinopril $10 \mathrm{mg} / \mathrm{day}$, meloxicam $15 \mathrm{mg} / \mathrm{day}$, metoprolol 50 mg/day, omeprazole $20 \mathrm{mg} /$ day, trimethoprim/sulfamethoxazole $1600 / 320 \mathrm{mg} /$ day (for skin breakdown over swollen lower extremities), tramadol $150 \mathrm{mg} /$ day, and trazodone $150 \mathrm{mg} /$ day.

${ }^{5}$ Other scheduled oral medications included asenapine $15 \mathrm{mg} / \mathrm{day}$, gabapentin $900 \mathrm{mg} / \mathrm{day}$, lisinopril $10 \mathrm{mg} / \mathrm{day}$, meloxicam $15 \mathrm{mg} / \mathrm{day}$, metoprolol 50 mg/day, omeprazole $20 \mathrm{mg} /$ day, tramadol $150 \mathrm{mg} /$ day, and trazodone $150 \mathrm{mg} / \mathrm{day}$.

${ }^{6}$ Other scheduled oral medications included asenapine $15 \mathrm{mg} /$ day, furosemide $40 \mathrm{mg} /$ day, gabapentin $900 \mathrm{mg} / \mathrm{day}$, lisinopril $10 \mathrm{mg} / \mathrm{day}$, metoprolol $50 \mathrm{mg} / \mathrm{day}$, omeprazole $20 \mathrm{mg} /$ day, tramadol $150 \mathrm{mg} /$ day, and trazodone $150 \mathrm{mg} / \mathrm{day}$.

${ }^{7}$ Other scheduled oral medications included asenapine $15 \mathrm{mg} /$ day, furosemide $20 \mathrm{mg} /$ day, gabapentin $1200 \mathrm{mg} / \mathrm{day}$, lisinopril $10 \mathrm{mg} / \mathrm{day}$, metoprolol 50 mg/day, omeprazole $20 \mathrm{mg} /$ day, tramadol $200 \mathrm{mg}$ /day, and trazodone $150 \mathrm{mg} /$ day.

${ }^{8}$ Other scheduled oral medications included asenapine $15 \mathrm{mg} / \mathrm{day}$, furosemide $20 \mathrm{mg} / \mathrm{day}$, gabapentin $1200 \mathrm{mg} / \mathrm{day}$, metoprolol $50 \mathrm{mg} / \mathrm{day}$, omeprazole $20 \mathrm{mg} /$ day, tramadol $200 \mathrm{mg} /$ day, and trazodone $150 \mathrm{mg} /$ day.

${ }^{9}$ Other scheduled oral medications included asenapine $15 \mathrm{mg} /$ day, furosemide $20 \mathrm{mg} / \mathrm{day}$, gabapentin $1200 \mathrm{mg} / \mathrm{day}$, metoprolol $50 \mathrm{mg} / \mathrm{day}$, omeprazole $20 \mathrm{mg} /$ day, polyethylene glycol $17 \mathrm{~g} /$ day, tramadol $200 \mathrm{mg} / \mathrm{day}$, and trazodone $150 \mathrm{mg} /$ day.

ideas in addition to increased levels of energy. His VPA concentrations were monitored closely with gradual increases in his enterocoated divalproex sodium. Despite increasing his daily dose and switching to concentrate and then back to enterocoated divalproex sodium, the dose had to be progressively increased to a total of $4000 \mathrm{mg} /$ day to continue to have a therapeutic response and therapeutic levels. By the time of discharge, the patient's mood had become more euthymic. He was discharged after 10 weeks of inpatient management in stable condition and with a medication regimen including VPA at $4000 \mathrm{mg} /$ day. This patient was remarkable because, in order to maintain the therapeutic response and a VPA level around $70 \mu \mathrm{g} / \mathrm{mL}$, progressively higher doses from 1500 to $4000 \mathrm{mg} / \mathrm{day}$ were needed to the point that the last VPA C/D ratio multiplied by 1000 had a value remarkably low (at 17) while being on a high dose of $4000 \mathrm{mg} /$ day and with a VPA concentration of only $67 \mu \mathrm{g} / \mathrm{mL}$. The mean C/D ratio multiplied by 1000 was 25 with a range from 17 to 33 (Table 3). As a matter of fact, in spite of the limited number of VPA concentrations, there was a very strong correlation $(r=0.97 ; p<0.001)$ between the number of days of admission and the dose, indicating that, with an increasing length of admission, the dose increased, and this high value remained after correcting for VPA concentrations using a partial correlation $(r=0.96 ; p<0.001)$ (Table 3, footnote 1). This is compatible with a progressive autoinduction; as the time after admission increased, it was necessary to increase the VPA dose. The patient was discharged on $4000 \mathrm{mg} /$ day; we do not know what happened after discharge, except that the patient had no relapses for 2 years after this admission.

Considering the need for higher doses to maintain the same VPA concentration, the DIPS score was 5 (scoring 1 point each for questions $2,3,4,7$, and 8), indicating a "probable" relationship between VPA and autoinduction activity.

3.3. Case 3. Patient 3 was a Caucasian male nonsmoker with a history of tuberous sclerosis, which manifested as seizure disorder and mental retardation. His initial weight was $71 \mathrm{Kg}$. He had been an inpatient at a state psychiatric hospital for 22 years before the senior author started to manage his treatment (day 1 ) when the patient was 48 years old. Two years later he developed a right renal mass, which was highly suspicious for renal cell carcinoma on biopsy. It was followed by a right-sided nephrectomy and cholecystectomy (day 860). However, the final pathology suggested that 
the mass was actually angiomyolipoma, which is common if there is renal involvement in patients with tuberous sclerosis. Thorough investigation for left-sided pathology indicated that his left kidney was functioning well with stable masses present on CT. From day 1322, the patient progressively worsened with new-onset episodes of ataxia and confusion. High clinical suspicion for a brain mass led the senior author to investigate with MRI. The results indicated that the patient had a mass in the right lateral ventricle "suggestive of giant cell astrocytoma" and that "foci of enhancement at the gray-white junction and numerous signal abnormalities in the skull suggest the possibility of metastatic disease." Giant cell astrocytomas occur in $6-14 \%$ of patients with tuberous sclerosis and should be suspected when there is a new focal deficit, signs of increased intracranial pressure, or unexplained behavioral changes. After day 1420, when the brain tumor was diagnosed, we started trying to reduce the VPA dose and manage it on the basis of the patient's comfort rather than the VPA concentration level.

During the long follow-up of more than 4 years (almost 1500 days) described in Table 4, the patient had therapeutic levels of phenytoin initially with $500 \mathrm{mg} /$ day and at the end with $400 \mathrm{mg} /$ day. VPA showed a completely different pattern, requiring a progressive increase in the dose to keep VPA therapeutic concentrations $>50 \mu \mathrm{g} / \mathrm{mL}$. On day 1 the VPA dose was $3375 \mathrm{mg} /$ day, on day 400 it was $5000 \mathrm{mg} /$ day, on day 943 it was $9000 \mathrm{mg} / \mathrm{day}$, and on day 1029 it was $10500 \mathrm{mg} / \mathrm{day}$, which was maintained until it was clear that his physical deterioration was due to a brain tumor. At that time other medications were discontinued, only leaving phenytoin and a lower VPA dose (Table 4).

Despite the necessity of increasing the VPA dose to this very high dosage, the phenytoin dose remained stable with normal blood levels in the therapeutic range. This suggests that the progressive increase in VPA metabolism was not associated with an increase in phenytoin metabolism. The VPA C/D ratios in this patient were extremely low, frequently lower than 10 . The mean C/D ratio multiplied by 1000 for 70 therapeutic concentrations was 8 with a range from 5 to 18 (Table 3 ). As a matter of fact, there was a very strong correlation $(r=0.97 ; p<0.001)$ between the number of days past admission and the dose, indicating that with an increasing length of admission, the dose increased, and this significance remained after correcting for VPA concentrations using a partial correlation $(r=0.89 ; p<0.001)$ (Table 4, footnote 1). This is compatible with a progressive autoinduction.

Using the DIPS as in the previous cases, the total score was 5 (scoring 1 point each for questions 2, 3, 4, 7, and 8), indicating a "probable" relationship between VPA and the autoinduction of its metabolism.

\section{Discussion}

4.1. Limitations. These 3 cases reflect 3 extremely challenging patients who required very high doses of VPA $>4000 \mathrm{mg} /$ day to maintain VPA therapeutic levels. As usual in these challenging cases, the pharmacological data is somewhat limited since patients were treated with polypharmacy and went through complex changes in medications. In spite of the data limitations, we think that these cases need to be published to acknowledge that while these patients are very rare, they exist. In support of the above findings, however, the senior author was closely involved in the treatment of the 3 patients and all VPA concentrations were measured in the same lab. It is rare to see publications describe so many large measures of VPA concentrations.

The data is limited but undeniable and should indicate to any clinician that these 3 patients needed daily doses of VPA to get therapeutic VPA concentrations. The second and greater limitation in analyzing these cases is our interpretation of the data many years after they were collected-in the third case, almost 20 years. It has required that much time to accumulate evidence in the literature to understand what happened and to realize that VPA may be an inducer; in fact, it can induce its own metabolism. Therefore, although these VPA concentrations were collected prospectively and used to modify VPA doses, they were reviewed retrospectively to provide the unified hypothesis that it is possible that these high VPA doses were required because these 3 patients were unusually sensitive to VPA autoinduction. In retrospect, after having a possible pharmacological explanation now after many years, it would have been better to collect more frequent TDM data, but what is described is what is available. Although we acknowledge that the data is limited and our interpretation is even more limited, we have tried to support our interpretation through the use of statistical tests and a validated scale.

4.2. High Doses of VPA May Be Explained by VPA Autoinduction. We think these cases contribute to the scarce literature by indicating that clinicians must be aware that VPA may behave as an inducer. In Cases 1 and 3, patients with likely VPA autoinduction presented significant clinical challenges to the senior author, who had no idea why the patients required much higher VPA dosages to obtain therapeutic VPA concentrations. Case 2 was identified only 4 years ago when the senior author realized that VPA autoinduction was clinically relevant for some peculiar patients. As a matter of fact, Case 2 was identified by the third author, who had rarely seen similar cases. The senior author suggested to her that these cases were probably explained by autoinduction and she was able to identify this patient as a candidate for VPA autoinduction shortly after admission.

The first patient was very challenging, probably the most challenging patient in the senior author's career, even with his more than 25-year history of treating treatmentrefractory patients. The patient metabolized the CYP1A2 drugs clozapine and olanzapine normally but got intoxicated on clozapine during an infection [34]. He appeared unusual because he needed $5250 \mathrm{mg} /$ day of VPA concentrate for several years to get therapeutic VPA concentrations. The senior author had experience in switching many patients back and forth from VPA concentrate to divalproex sodium using the same doses and getting similar VPA concentrations. In fact, the US prescribing information from the drug manufacturer recommended and continues to recommend initiating the same total daily doses when converting a patient from VPA to divalproex sodium. A published study 
TABle 4: VPA C/D ratio in Case 3.

\begin{tabular}{|c|c|c|c|c|c|c|c|}
\hline \multirow{2}{*}{ Day $^{1}$} & \multicolumn{5}{|c|}{ VPA } & \multicolumn{2}{|c|}{ Phenytoin } \\
\hline & Formulation & $\operatorname{Dose}^{1}$ (mg/day) & Concentration $(\mu \mathrm{g} / \mathrm{mL})$ & $\mathrm{C} / \mathrm{D}$ ratio & $\mathrm{C} / \mathrm{D}$ ratio $\times 1000$ & Dose (mg/day) & Concentration $(\mu \mathrm{g} / \mathrm{mL})$ \\
\hline \multicolumn{8}{|c|}{ All 137 VPA concentrations $(\mathrm{C} / \mathrm{D}$ ratio $\times 1000:$ mean $\pm \mathrm{SD}=8 \pm 3.5$, range $=3-20)$} \\
\hline \multicolumn{8}{|c|}{70 therapeutic $^{2}$ VPA concentrations $(C / D$ ratio $\times 1000:$ mean $\pm S D=9 \pm 3.4$, range $=5-18)$} \\
\hline $1^{3}$ & ECDVNa & 3375 & 46 & 0.014 & 14 & 500 & 15 \\
\hline $33^{3}$ & ECDVNa & 3375 & 59 & 0.017 & 17 & 500 & 18 \\
\hline $62^{3}$ & ECDVNa & 3375 & 43 & 0.013 & 13 & 500 & 16 \\
\hline $86^{3}$ & Concentrate & 3350 & 22 & 0.007 & 7 & 500 & \\
\hline $117^{3}$ & ECDVNa & 3450 & 43 & 0.012 & 12 & 500 & 11 \\
\hline $147^{3}$ & ECDVNa & 3375 & 38 & 0.011 & 11 & 500 & 10 \\
\hline $162^{3}$ & Concentrate & 3450 & 9 & 0.003 & 3 & 500 & \\
\hline $174^{3}$ & Concentrate & 3450 & 28 & 0.008 & 8 & 500 & 18 \\
\hline $177^{3}$ & Concentrate & 3450 & 31 & 0.009 & 9 & 500 & 18 \\
\hline $189^{3}$ & ECDVNa & 3375 & 36 & 0.011 & 11 & 500 & \\
\hline $202^{3}$ & ECDVNa & 3750 & 40 & 0.011 & 11 & 500 & 10 \\
\hline $208^{3}$ & ECDVNa & 4125 & 40 & 0.010 & 10 & 500 & 14 \\
\hline $212^{3}$ & ECDVNa & 4500 & 68 & 0.015 & 15 & 500 & 15 \\
\hline $244^{3}$ & ECDVNa & 4500 & 61 & 0.014 & 14 & 500 & 15 \\
\hline $274^{3}$ & ECDVNa & 4500 & 67 & 0.015 & 15 & 500 & 15 \\
\hline $307^{3}$ & ECDVNa & 4500 & 46 & 0.010 & 10 & 500 & 23 \\
\hline $310^{3}$ & ECDVNa & 4500 & 50 & 0.011 & 11 & 0 & 23 \\
\hline $313^{3}$ & ECDVNa & 4500 & 39 & 0.009 & 9 & 500 & 10 \\
\hline $316^{3}$ & ECDVNa & 4500 & 81 & 0.018 & 18 & 500 & 11 \\
\hline $320^{3}$ & ECDVNa & 4500 & 31 & 0.007 & 7 & 500 & 15 \\
\hline $324^{3}$ & ECDVNa & 4500 & 46 & 0.010 & 10 & 500 & 16 \\
\hline $335^{3}$ & ECDVNa & 5000 & 64 & 0.013 & 13 & 500 & 19 \\
\hline $350^{3}$ & ECDVNa & 5000 & 75 & 0.015 & 15 & 500 & 24 \\
\hline $398^{3}$ & ECDVNa & 5000 & 52 & 0.010 & 10 & 460 & 16 \\
\hline $400^{3}$ & ECDVNa & 5000 & 85 & 0.017 & 17 & 460 & 11 \\
\hline $430^{3}$ & ECDVNa & 5000 & 59 & 0.012 & 12 & 460 & 16 \\
\hline $439^{3}$ & ECDVNa & 5000 & 65 & 0.013 & 13 & 460 & 18 \\
\hline $470^{3}$ & ECDVNa & 5000 & 54 & 0.011 & 11 & 460 & 16 \\
\hline $502^{3}$ & ECDVNa & 5000 & 53 & 0.011 & 11 & 460 & 20 \\
\hline $530^{4}$ & ECDVNa & 5000 & 77 & 0.015 & 15 & 460 & 17 \\
\hline $559^{4}$ & ECDVNa & 5000 & 50 & 0.010 & 10 & 460 & 13 \\
\hline $590^{5}$ & ECDVNa & 5000 & 48 & 0.010 & 10 & 460 & 12 \\
\hline $621^{6}$ & ECDVNa & 5000 & 37 & 0.007 & 7 & 460 & 10 \\
\hline $635^{6}$ & ECDVNa & 5000 & 39 & 0.008 & 8 & 460 & 11 \\
\hline $646^{6}$ & ECDVNa & 5250 & 35 & 0.007 & 7 & 460 & 13 \\
\hline $681^{7}$ & ECDVNa & 5250 & 37 & 0.007 & 7 & 460 & 8 \\
\hline $713^{7}$ & ECDVNa & 5250 & 46 & 0.009 & 9 & 460 & 7 \\
\hline $734^{7}$ & ECDVNa & 5250 & 40 & 0.008 & 8 & 460 & 10 \\
\hline $762^{7}$ & ECDVNa & 6000 & 53 & 0.009 & 9 & 460 & 9 \\
\hline $770^{7}$ & ECDVNa & 6000 & 43 & 0.007 & 7 & 460 & 8 \\
\hline $798^{7}$ & ECDVNa & 6000 & 23 & 0.004 & 4 & 460 & 9 \\
\hline $806^{7}$ & ECDVNa & 6000 & 32 & 0.005 & 5 & 460 & 10 \\
\hline $817^{7}$ & ECDVNa & 7500 & 36 & 0.005 & 5 & 200 & 9 \\
\hline $831^{7}$ & ECDVNa & 7500 & 43 & 0.006 & 6 & 460 & 5 \\
\hline $838^{7}$ & ECDVNa & 7500 & 47 & 0.006 & 6 & 460 & 15 \\
\hline $846^{7}$ & ECDVNa & 7500 & 24 & 0.003 & 3 & 460 & 10 \\
\hline $852^{7}$ & ECDVNa & 7500 & 35 & 0.005 & 5 & 460 & 8 \\
\hline $860^{7}$ & ECDVNa & 7500 & 51 & 0.007 & 7 & 460 & \\
\hline
\end{tabular}


TABle 4: Continued.

\begin{tabular}{|c|c|c|c|c|c|c|c|}
\hline \multirow{2}{*}{ Day $^{1}$} & \multicolumn{5}{|c|}{ VPA } & \multicolumn{2}{|c|}{ Phenytoin } \\
\hline & Formulation & $\operatorname{Dose}^{1}$ (mg/day) & Concentration $(\mu \mathrm{g} / \mathrm{mL})$ & $\mathrm{C} / \mathrm{D}$ ratio & $\mathrm{C} / \mathrm{D}$ ratio $\times 1000$ & Dose (mg/day) & Concentration $(\mu \mathrm{g} / \mathrm{mL})$ \\
\hline $866^{7}$ & ECDVNa & 7500 & 42 & 0.006 & 6 & 460 & 3 \\
\hline $888^{7}$ & ECDVNa & 7500 & 71 & 0.009 & 9 & 460 & 20 \\
\hline $890^{7}$ & ECDVNa & 7500 & 81 & 0.011 & 11 & 460 & 20 \\
\hline $916^{7}$ & ECDVNa & 7500 & 45 & 0.006 & 6 & 460 & 7 \\
\hline $919^{7}$ & ECDVNa & 7500 & 46 & 0.006 & 6 & 460 & 7 \\
\hline $929^{7}$ & ECDVNa & 8250 & 43 & 0.005 & 5 & 460 & \\
\hline $943^{7}$ & ECDVNa & 9000 & 43 & 0.005 & 5 & 460 & \\
\hline $950^{7}$ & ECDVNa & 9000 & 50 & 0.006 & 6 & 460 & \\
\hline $957^{7}$ & ECDVNa & 9000 & 75 & 0.008 & 8 & 460 & \\
\hline $964^{7}$ & ECDVNa & 9000 & 37 & 0.004 & 4 & 460 & \\
\hline $971^{7}$ & ECDVNa & 9000 & 28 & 0.003 & 3 & 460 & \\
\hline $972^{7}$ & ECDVNa & 9000 & 44 & 0.005 & 5 & 460 & 8 \\
\hline $979^{7}$ & ECDVNa & 9000 & 64 & 0.007 & 7 & 460 & 6 \\
\hline $985^{7}$ & ECDVNa & 9000 & 38 & 0.004 & 4 & 460 & 9 \\
\hline $989^{7}$ & ECDVNa & 9000 & 50 & 0.006 & 6 & 460 & 8 \\
\hline $992^{7}$ & ECDVNa & 9000 & 59 & 0.007 & 7 & 460 & 9 \\
\hline $999^{7}$ & ECDVNa & 9000 & 54 & 0.006 & 6 & 460 & 6 \\
\hline $1014^{7}$ & ECDVNa & 9000 & 35 & 0.004 & 4 & 460 & 6 \\
\hline $1020^{7}$ & ECDVNa & 9000 & 42 & 0.005 & 5 & 460 & 5 \\
\hline $1029^{7}$ & ECDVNa & 10500 & 43 & 0.004 & 4 & 460 & 7 \\
\hline $1035^{7}$ & ECDVNa & 10500 & 102 & 0.010 & 10 & 460 & 6 \\
\hline $1039^{7}$ & ECDVNa & 10500 & 54 & 0.005 & 5 & 460 & 1 \\
\hline $1042^{7}$ & ECDVNa & 10500 & 77 & 0.007 & 7 & 460 & 6 \\
\hline $1056^{7}$ & ECDVNa & 10500 & 120 & 0.011 & 11 & 460 & 6 \\
\hline $1062^{7}$ & ECDVNa & 10500 & 39 & 0.004 & 4 & 460 & 8 \\
\hline $1064^{7}$ & ECDVNa & 10500 & 47 & 0.004 & 4 & 460 & 7 \\
\hline $1070^{7}$ & ECDVNa & 10500 & 56 & 0.005 & 5 & 460 & 6 \\
\hline $1080^{7}$ & ECDVNa & 10500 & 51 & 0.005 & 5 & 460 & 10 \\
\hline $1091^{7}$ & ECDVNa & 10500 & 54 & 0.005 & 5 & 460 & 11 \\
\hline $1098^{7}$ & ECDVNa & 10500 & 63 & 0.006 & 6 & 460 & 12 \\
\hline $1105^{7}$ & ECDVNa & 10500 & 49 & 0.005 & 5 & 460 & 12 \\
\hline $1112^{7}$ & ECDVNa & 10500 & 47 & 0.004 & 4 & 460 & 8 \\
\hline $1119^{7}$ & ECDVNa & 10500 & 51 & 0.005 & 5 & 460 & 6 \\
\hline $1133^{7}$ & ECDVNa & 10500 & 91 & 0.009 & 9 & 460 & 7 \\
\hline $1148^{7}$ & ECDVNa & 10500 & 50 & 0.005 & 5 & 460 & 13 \\
\hline $1163^{7}$ & ECDVNa & 10500 & 40 & 0.004 & 4 & 460 & 9 \\
\hline $1168^{7}$ & ECDVNa & 10500 & 62 & 0.006 & 6 & 460 & 10 \\
\hline $1175^{7}$ & ECDVNa & 10500 & 63 & 0.006 & 6 & 460 & 13 \\
\hline $1182^{7}$ & ECDVNa & 10500 & 110 & 0.010 & 10 & 460 & 11 \\
\hline $1184^{7}$ & ECDVNa & 10500 & 61 & 0.006 & 6 & 460 & 10 \\
\hline $1189^{7}$ & ECDVNa & 10500 & 56 & 0.005 & 5 & 460 & 10 \\
\hline $1196^{7}$ & ECDVNa & 14000 & 133 & 0.010 & 10 & 460 & 9 \\
\hline $1210^{7}$ & ECDVNa & 10500 & 67 & 0.006 & 6 & 460 & 13 \\
\hline $1217^{7}$ & ECDVNa & 10500 & 65 & 0.006 & 6 & 460 & 14 \\
\hline $1224^{7}$ & ECDVNa & 10500 & 87 & 0.008 & 8 & 460 & 11 \\
\hline $1231^{7}$ & ECDVNa & 10500 & 70 & 0.007 & 7 & 460 & 13 \\
\hline $1245^{7}$ & ECDVNa & 10500 & 65 & 0.006 & 6 & 460 & 15 \\
\hline $1252^{7}$ & ECDVNa & 10500 & 97 & 0.009 & 9 & 460 & 9 \\
\hline $1259^{7}$ & ECDVNa & 10500 & 77 & 0.007 & 7 & 460 & 13 \\
\hline $1266^{7}$ & ECDVNa & 10500 & 56 & 0.005 & 5 & 460 & 12 \\
\hline
\end{tabular}


TABLE 4: Continued.

\begin{tabular}{|c|c|c|c|c|c|c|c|}
\hline \multirow{2}{*}{ Day $^{1}$} & \multicolumn{5}{|c|}{ VPA } & \multicolumn{2}{|r|}{ Phenytoin } \\
\hline & Formulation & $\operatorname{Dose}^{1}$ (mg/day) & Concentration $(\mu \mathrm{g} / \mathrm{mL})$ & $\mathrm{C} / \mathrm{D}$ ratio & $\mathrm{C} / \mathrm{D}$ ratio $\times 1000$ & Dose (mg/day) & Concentration $(\mu \mathrm{g} / \mathrm{mL})$ \\
\hline $1273^{7}$ & ECDVNa & 10500 & 97 & 0.009 & 9 & 460 & 14 \\
\hline $1280^{7}$ & ECDVNa & 10500 & 60 & 0.006 & 6 & 460 & 16 \\
\hline $1287^{8}$ & ECDVNa & 10500 & 39 & 0.004 & 4 & 460 & 19 \\
\hline $1294^{8}$ & ECDVNa & 10500 & 103 & 0.010 & 10 & 460 & 15 \\
\hline $1301^{8}$ & ECDVNa & 10500 & 48 & 0.005 & 5 & 460 & 19 \\
\hline $1307^{8}$ & ECDVNa & 10500 & 72 & 0.007 & 7 & 460 & 13 \\
\hline $1316^{8}$ & ECDVNa & 10500 & 54 & 0.005 & 5 & 460 & 13 \\
\hline $1322^{8}$ & ECDVNa & 10500 & 71 & 0.007 & 7 & 460 & 13 \\
\hline $1329^{8}$ & ECDVNa & 10500 & 75 & 0.007 & 7 & 460 & 13 \\
\hline $1336^{8}$ & ECDVNa & 10500 & 98 & 0.009 & 9 & 460 & 12 \\
\hline $1344^{8}$ & ECDVNa & 10500 & 93 & 0.009 & 9 & 460 & 11 \\
\hline $1350^{8}$ & ECDVNa & 10500 & 65 & 0.006 & 6 & 460 & 15 \\
\hline $1357^{8}$ & ECDVNa & 10500 & 58 & 0.006 & 6 & 460 & 23 \\
\hline $1364^{8}$ & ECDVNa & 10500 & 73 & 0.007 & 7 & 460 & 18 \\
\hline $1371^{8}$ & ECDVNa & 10500 & 106 & 0.010 & 10 & 460 & 24 \\
\hline $1373^{8}$ & ECDVNa & 10500 & 106 & 0.010 & 10 & 460 & 20 \\
\hline $1378^{8}$ & ECDVNa & 10500 & 89 & 0.008 & 8 & 460 & 15 \\
\hline $1386^{8}$ & ECDVNa & 10500 & 97 & 0.009 & 9 & 460 & 17 \\
\hline $1392^{8}$ & ECDVNa & 10500 & 72 & 0.007 & 7 & 460 & 21 \\
\hline $1393^{8}$ & ECDVNa & 10500 & 87 & 0.008 & 8 & 460 & 23 \\
\hline $1394^{8}$ & ECDVNa & 10500 & 122 & 0.012 & 12 & 230 & 22 \\
\hline $1395^{8}$ & ECDVNa & 3500 & 37 & 0.011 & 11 & 0 & 20 \\
\hline $1399^{8}$ & ECDVNa & 10500 & 130 & 0.012 & 12 & 400 & 8 \\
\hline $1406^{8}$ & ECDVNa & 10500 & 94 & 0.009 & 9 & 400 & 10 \\
\hline $1413^{8}$ & ECDVNa & 10500 & 126 & 0.012 & 12 & 400 & 12 \\
\hline $1420^{8}$ & ECDVNa & 10500 & 108 & 0.010 & 10 & 400 & 12 \\
\hline $1427^{8}$ & ECDVNa & 6000 & 59 & 0.010 & 10 & 400 & 21 \\
\hline $1435^{8}$ & ECDVNa & 9000 & 110 & 0.012 & 12 & 400 & 5 \\
\hline $1440^{8}$ & ECDVNa & 9000 & 86 & 0.010 & 10 & 400 & 8 \\
\hline $1444^{8}$ & ECDVNa & 9000 & 82 & 0.009 & 9 & 400 & 10 \\
\hline $1448^{8}$ & ECDVNa & 9000 & 147 & 0.016 & 16 & 400 & 10 \\
\hline $1454^{7}$ & ECDVNa & 7000 & 93 & 0.013 & 13 & 400 & 14 \\
\hline $1457^{9}$ & ECDVNa & 7000 & 138 & 0.020 & 20 & 400 & 11 \\
\hline $1461^{10}$ & ECDVNa & 7000 & 72 & 0.010 & 10 & 400 & 13 \\
\hline $1470^{11}$ & ECDVNa & 7000 & 101 & 0.014 & 14 & 400 & 13 \\
\hline 1478 & ECDVNa & 7000 & 113 & 0.016 & 16 & 400 & 7 \\
\hline 1483 & ECDVNa & 7000 & 97 & 0.014 & 14 & 400 & 6 \\
\hline
\end{tabular}

C/D: concentration-to-dose; ECDVNa: enterocoated divalproex sodium; VPA: valproic acid.

${ }^{1}$ After day 1420, VPA dose was guided more by physical comfort than VPA concentrations; therefore, these latter days were eliminated to calculate the Pearson correlation between day of admission and VPA dose, which was $r=0.92(p<0.001)$; VPA dose remained very high in a partial correlation while controlling for VPA concentration: $r=0.89(p<0.001)$. This is compatible with a progressive autoinduction indicating, at least with dose range, that it was necessary to increase the dose as the duration lengthened. When all values (including those after day 1420) were used to calculate correlations, the $r$ values were, not surprisingly, slightly reduced both for the total correlation of $r=0.83(p<0.001)$ and the partial correlation of $r=0.78(p<0.001)$.

${ }^{2} 50-100 \mu \mathrm{g} / \mathrm{mL}$ concentrations are considered therapeutic concentrations. As this patient has too many nontherapeutic concentrations, it may be better to compare with other patients using only the VPA therapeutic concentrations.

${ }^{3}$ Other scheduled oral medications included benztropine $4 \mathrm{mg} /$ day, mesoridazine $200 \mathrm{mg} /$ day, lorazepam $6 \mathrm{mg} / \mathrm{day}$, and risperidone $12 \mathrm{mg} / \mathrm{day}$.

${ }^{4}$ Other scheduled oral medications included benztropine $4 \mathrm{mg}$ /day, lorazepam $6 \mathrm{mg} /$ day, and risperidone $12 \mathrm{mg} /$ day.

${ }^{5}$ Other scheduled oral medications included benztropine $4 \mathrm{mg} /$ day, lorazepam $6 \mathrm{mg} / \mathrm{day}$, and risperidone $4 \mathrm{mg} /$ day.

${ }^{6}$ Other scheduled oral medications included benztropine $4 \mathrm{mg} /$ day and lorazepam $6 \mathrm{mg} /$ day.

${ }^{7}$ Other scheduled oral medications included lorazepam $6 \mathrm{mg} / \mathrm{day}$

${ }^{8}$ Other scheduled oral medications included lorazepam $6 \mathrm{mg} /$ day and trazodone $150 \mathrm{mg} /$ day.

${ }^{9}$ Other scheduled oral medications included lorazepam $4 \mathrm{mg} /$ day.

${ }^{10}$ Other scheduled oral medications included lorazepam $3 \mathrm{mg} /$ day.

${ }^{11}$ Other scheduled oral medications included lorazepam $1 \mathrm{mg} /$ day. 
reported a statistically significant decrease of $14.4 \%(p=$ 0.001 ) in VPA plasma concentrations upon switching dosage forms from divalproex sodium to VPA [35]. Therefore, the senior author expected a minor increase of around $14.4 \%$ in switching from $5250 \mathrm{mg} /$ day of VPA concentrate but, instead, he intoxicated the patient. The VPA concentration went from the $80 \mathrm{~s} \mu \mathrm{g} / \mathrm{mL}$ to $145 \mu \mathrm{g} / \mathrm{mL}$ and required halving the dose to $2000 \mathrm{mg} /$ day of divalproex sodium to get VPA concentrations in the $80 \mathrm{~s} \mu \mathrm{g} / \mathrm{mL}$. In retrospect, during treatment with VPA concentrate, the VPA C/D ratio multiplied by 1000 was extremely low, at a mean of 15 and a range of $10-21$, indicating an extraordinarily high capacity to metabolize VPA. This is compatible with VPA concentrate inducing its own metabolism. We propose that after 4 weeks on divalproex sodium the autoinduction was lost and the patient's metabolism normalized, with a mean VPA C/D ratio multiplied by 1000 of 39 and a range of 28 to 48 . We cannot explain why this patient's VPA concentrate appeared to induce its own metabolism while divalproex sodium did not; we assume this patient had some rare genetic variation that explains his peculiar response.

The second patient had a relatively short admission ( $<60$ days) but demonstrated a very high and significant correlation between length of admission and VPA dose. The final C/D ratio was 17 , extremely low. This type of patient is probably more common than Case 1; his treating psychiatrist, the third author, has seen several similar cases in her 25-year practice in patients with severe mental illness including 20 years at this psychiatric hospital.

The third patient probably deserved a Guinness record since he was treated with $10500 \mathrm{mg} /$ day for 400 days and had a VPA C/D ratio multiplied by 1000 which yielded a value less than 10 most of the time. We have the impression that progressive VPA autoinduction explained the need to go from 3450 to $10500 \mathrm{mg} /$ day to achieve and maintain VPA concentrations $>50 \mu \mathrm{g} / \mathrm{mL}$. It is possible that phenytoin treatment contributed in some way to the facilitation of VPA autoinduction, since phenytoin is a major inducer and can displace VPA from plasmatic proteins. It is remarkable that although increases in VPA dosage were needed to get therapeutic VPA concentrations, the phenytoin dosage needed to obtain therapeutic phenytoin concentrations was relatively stable throughout this time period. Phenytoin doses ranged from $500 \mathrm{mg} /$ day at the beginning to $400 \mathrm{mg} /$ day at the end. This minor reduction in dosage may be explained by the greater VPA concentrations at the end. VPA is an inhibitor of phenytoin metabolism. Unfortunately, 20 years ago, free VPA and phenytoin concentrations were not available at this psychiatric hospital. It would have been important to measure them [29].

\subsection{The Pharmacological Mechanism behind VPA Induction.} The induction of metabolic enzymes such as UGTs implies that the amount of these proteins increases when they are induced; this is almost always explained by increasing protein synthesis mediated by the so-called nuclear receptors (constitutive androstane, estrogen, glucocorticoid receptors, and pregnane $\mathrm{X}$ receptors) or other transcription factors such as aryl hydrocarbon receptors. The potent AED inducers (carbamazepine, phenytoin, and phenobarbital) bind to the pregnane X receptors. Phenytoin and phenobarbital appear to also bind to the constitutive androstane receptors. VPA is a less potent inducer but probably works in a similar way. An in vitro study suggested that VPA might also activate constitutive androstane receptor and pregnane $\mathrm{X}$ receptor pathways [14].

We think it is possible that these unusual patients needing very high VPA dosages have unusual genetic variants at the nuclear receptors, which made them very sensitive to VPA autoinduction.

\section{Disclaimer}

No commercial organizations had any role in the writing of this paper for publication.

\section{Conflict of Interests}

In the last 3 years, the authors had no conflict of interests.

\section{Acknowledgments}

The authors acknowledge Lorraine Maw, M. A., who helped in editing this paper, and Kay Marshall, who was at that time Lab Director at the Psychiatric Hospital, and her staff were very helpful with the collection and analyses of the blood samples during all of these years.

\section{References}

[1] G. M. Peterson and M. Naunton, "Valproate: a simple chemical with so much to offer," Journal of Clinical Pharmacy and Therapeutics, vol. 30, no. 5, pp. 417-421, 2005.

[2] Lexicomp, Drug Information Handbook, Lexi-Comp, Hudson, Ohio, USA, 23rd edition, 2014.

[3] P. N. Patsalos, D. J. Berry, B. F. D. Bourgeois et al., "Antiepileptic drugs-best practice guidelines for therapeutic drug monitoring: a position paper by the subcommission on therapeutic drug monitoring, ILAE Commission on Therapeutic Strategies," Epilepsia, vol. 49, no. 7, pp. 1239-1276, 2008.

[4] G. D. Anderson, "A mechanistic approach to antiepileptic drug interactions," Annals of Pharmacotherapy, vol. 32, no. 5, pp. 554563, 1998.

[5] C. L. DeVane, "Pharmacokinetics, drug interactions, and tolerability of valproate," Psychopharmacology Bulletin, vol. 37, supplement 2, pp. 25-42, 2003.

[6] J. Fleming and M. Chetty, "Psychotropic drug interactions with valproate," Clinical Neuropharmacology, vol. 28, no. 2, pp. 96101, 2005.

[7] T. K. L. Kiang, P. C. Ho, M. R. Anari, V. Tong, F. S. Abbott, and T. K. H. Chang, "Contribution of CYP2C9, CYP2A6, and CYP2B6 to valproic acid metabolism in hepatic microsomes from individuals with the CYP2C9* $1 /^{*} 1$ genotype," Toxicological Sciences, vol. 94, no. 2, pp. 261-271, 2006.

[8] G. Nagai, S. Ono, N. Yasui-Furukori, A. Nakamura, K. Mihara, and T. Kondo, "Formulations of valproate alter valproate metabolism: a single oral dose kinetic study," Therapeutic Drug Monitoring, vol. 31, no. 5, pp. 592-596, 2009. 
[9] U. A. Argikar and R. P. Remmel, "Effect of aging on glucuronidation of valproic acid in human liver microsomes and the role of UDP-glucuronosyltransferase UGT1A4, UGT1A8, and UGT1A10," Drug Metabolism and Disposition, vol. 37, no. 1, pp. 229-236, 2009.

[10] J. E. Fisher, H. Nau, and W. Löscher, "Alterations in the renal excretion of valproate and its metabolites after chronic treatment," Epilepsia, vol. 32, no. 1, pp. 146-150, 1991.

[11] W. D. Hooper, M. E. Franklin, P. Glue et al., "Effect of felbamate on valproic acid disposition in healthy volunteers: Inhibition of beta-oxidation," Epilepsia, vol. 37, no. 1, pp. 91-97, 1996.

[12] G. D. Anderson, M. K. Yau, B. E. Gidal et al., "Bidirectional interaction of valproate and lamotrigine in healthy subjects," Clinical Pharmacology \& Therapeutics, vol. 60, no. 2, pp. 145156, 1996.

[13] D. B. McLaughlin, J. A. Andrews, W. D. Hooper, G. R. Canned, M. J. Eadie, and R. G. Dickinson, "Apparent autoinduction of valproate $\beta$-oxidation in humans," British Journal of Clinical Pharmacology, vol. 49, no. 5, pp. 409-415, 2000.

[14] L. Cerveny, L. Svecova, E. Anzenbacherova et al., "Valproic acid induces CYP3A4 and MDR1 gene expression by activation of constitutive androstane receptor and pregnane $\mathrm{X}$ receptor pathways," Drug Metabolism and Disposition, vol. 35, no. 7, pp. 1032-1041, 2007.

[15] F. A. de Jong, J. M. van der Bol, R. H. J. Mathijssen et al., "Irinotecan chemotherapy during valproic acid treatment: pharmacokinetic interaction and hepatotoxicity," Cancer Biology \& Therapy, vol. 6, no. 9, pp. 1368-1374, 2007.

[16] L. Citrome, R. Josiassen, N. Bark, D. E. Salazar, and S. Mallikaarjun, "Pharmacokinetics of aripiprazole and concomitant lithium and valproate," Journal of Clinical Pharmacology, vol. 45, no. 1, pp. 89-93, 2005.

[17] N. Bergemann, K. R. Kress, F. Abu-Tair, A. Frick, and J. Kopitz, "Valproate lowers plasma concentration of olanzapine," Journal of Clinical Psychopharmacology, vol. 26, no. 4, pp. 432-434, 2006.

[18] T. Haslemo, K. Olsen, H. Lunde, and E. Molden, "Valproic acid significantly lowers serum concentrations of olanzapine-an interaction effect comparable with smoking," Therapeutic Drug Monitoring, vol. 34, no. 5, pp. 512-517, 2012.

[19] S. Botts, F. J. Diaz, V. Santoro et al., "Estimating the effects of co-medications on plasma olanzapine concentrations by using a mixed model," Progress in Neuro-Psychopharmacology and Biological Psychiatry, vol. 32, no. 6, pp. 1453-1458, 2008.

[20] E. Spina, C. D’Arrigo, V. Santoro et al., "Effect of valproate on olanzapine plasma concentrations in patients with bipolar or schizoaffective disorder," Therapeutic Drug Monitoring, vol. 31, no. 6, pp. 758-763, 2009.

[21] P. Finley and D. Warner, "Potential impact of valproic acid therapy on clozapine disposition," Biological Psychiatry, vol. 36, no. 7, pp. 487-488, 1994.

[22] L. P. Longo and C. Salzman, "Valproic acid effects on serum concentrations of clozapine and norclozapine," The American Journal of Psychiatry, vol. 152, no. 4, p. 650, 1995.

[23] A. Riesselman, B. Strobl, A. T. Cooley, and J. de Leon, "A case report that suggested that aspirin's effects on valproic acid metabolism may contribute to valproic acid's inducer effects on clozapine metabolism," Journal of Clinical Psychopharmacology, vol. 33, no. 6, pp. 812-814, 2013.

[24] F. J. Diaz, V. Santoro, E. Spina et al., "Estimating the size of the effects of co-medications on plasma clozapine concentrations using a model that controls for clozapine doses and confounding variables," Pharmacopsychiatry, vol. 41, no. 3, pp. 81-91, 2008.

[25] F. J. Diaz, C. B. Eap, N. Ansermot, S. Crettol, E. Spina, and J. De Leon, "Can valproic acid be an inducer of clozapine metabolism?” Pharmacopsychiatry, vol. 47, no. 3, pp. 89-96, 2014.

[26] R. Vrzal, A. Doricakova, A. Novotna et al., "Valproic acid augments vitamin D receptor-mediated induction of CYP24 by vitamin D3: a possible cause of valproic acid-induced osteomalacia?” Toxicology Letters, vol. 200, no. 3, pp. 146-153, 2011.

[27] J. de Leon, E. Spina, and F. J. Diaz, "Clobazam therapeutic drug monitoring: a comprehensive review of the literature with proposals to improve future studies," Therapeutic Drug Monitoring, vol. 35, no. 1, pp. 30-47, 2013.

[28] E. Spina and J. de Leon, "Clinical applications of CYP genotyping in psychiatry," Journal of Neural Transmission, vol. 122, no. 1, pp. 5-28, 2015.

[29] J. de Leon, J. L. Kiesel, M. W. Fleming, and B. Strobl, "Valproic acid toxicity associated with low dose of aspirin and low total valproic acid levels: a case report," Journal of Clinical Psychopharmacology, vol. 29, no. 5, pp. 509-511, 2009.

[30] R. Fernández-Pérez, J. M. Álvarez-Dobaño, J. Suárez-Antelo et al., "Eosinophilic pleural effusion associated with the addition of sodium valproate," Journal of Clinical Psychopharmacology, vol. 29, no. 3, pp. 310-311, 2009.

[31] K. T. Brady, S. C. Sonne, R. Anton, and J. C. Ballenger, "Valproate in the treatment of acute bipolar affective episodes complicated by substance abuse: a pilot study," Journal of Clinical Psychiatry, vol. 56, no. 3, pp. 118-121, 1995.

[32] J. R. Horn, P. D. Hansten, and L. N. Chan, "Proposal for a new tool to evaluate drug interaction cases," Annals of Pharmacotherapy, vol. 41, no. 4, pp. 674-680, 2007.

[33] G. Coffey, S. Botts, and J. de Leon, "Dosing differences between valproic acid concentrate and divalproex sodium: a case report," The Journal of Clinical Psychiatry, vol. 65, no. 5, pp. 724-725, 2004.

[34] J. de Leon and F. J. Diaz, "Serious respiratory infections can increase clozapine levels and contribute to side effects: a case report," Progress in Neuro-Psychopharmacology and Biological Psychiatry, vol. 27, no. 6, pp. 1059-1063, 2003.

[35] J. D. Sherr and D. L. Kelly, "Substitution of immediate-release valproic acid for divalproex sodium for adult psychiatric inpatients," Psychiatric Services, vol. 49, no. 10, pp. 1355-1357, 1998. 


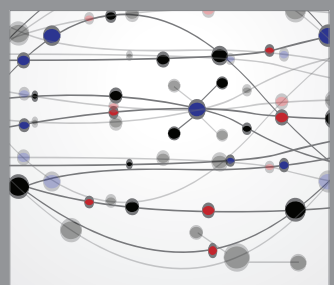

The Scientific World Journal
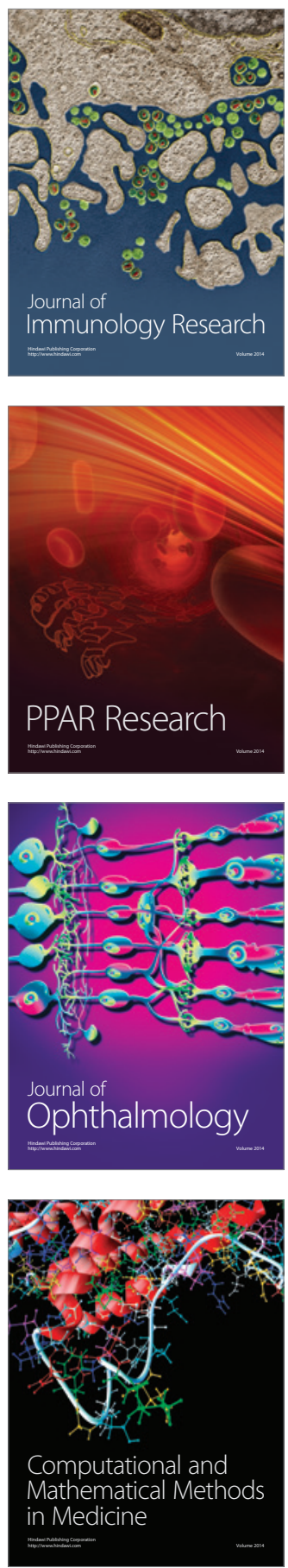

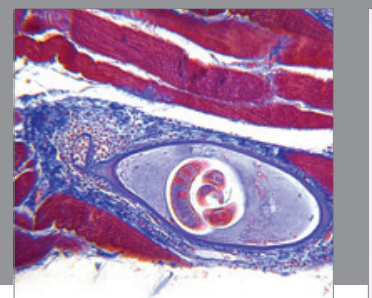

Gastroenterology

Research and Practice
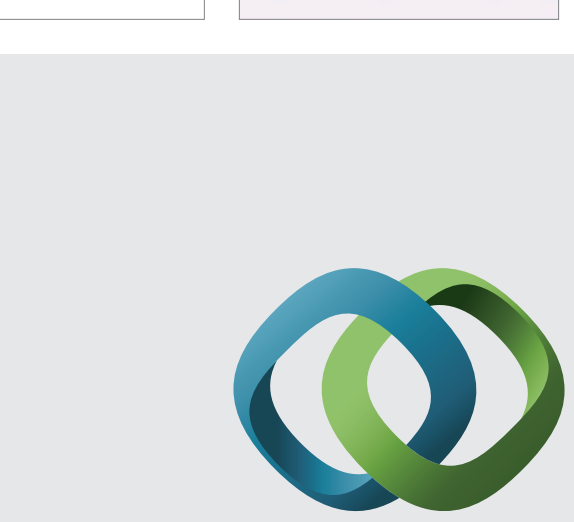

\section{Hindawi}

Submit your manuscripts at

http://www.hindawi.com
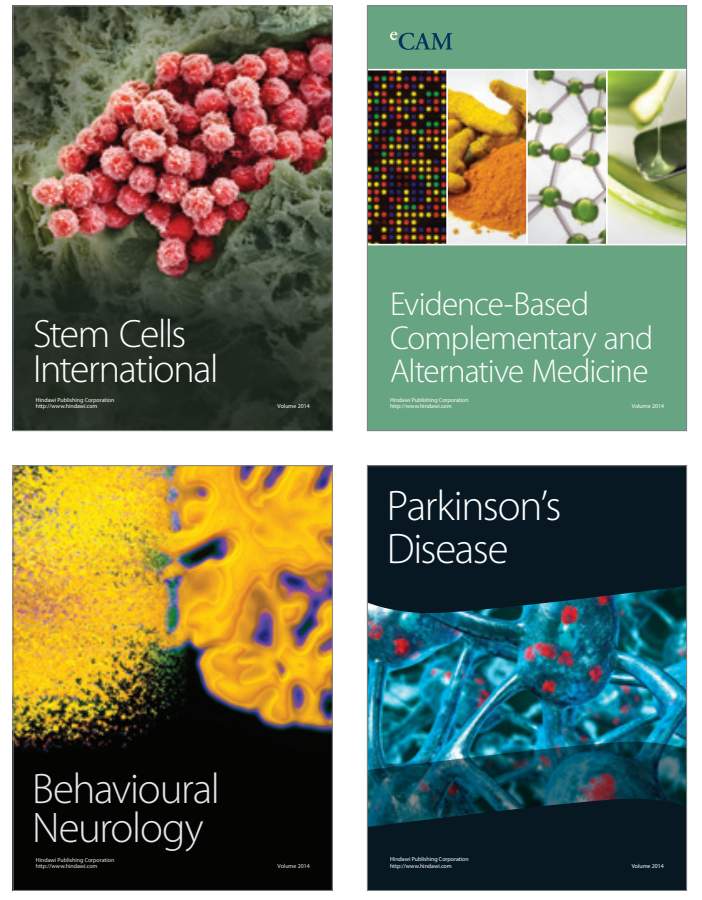
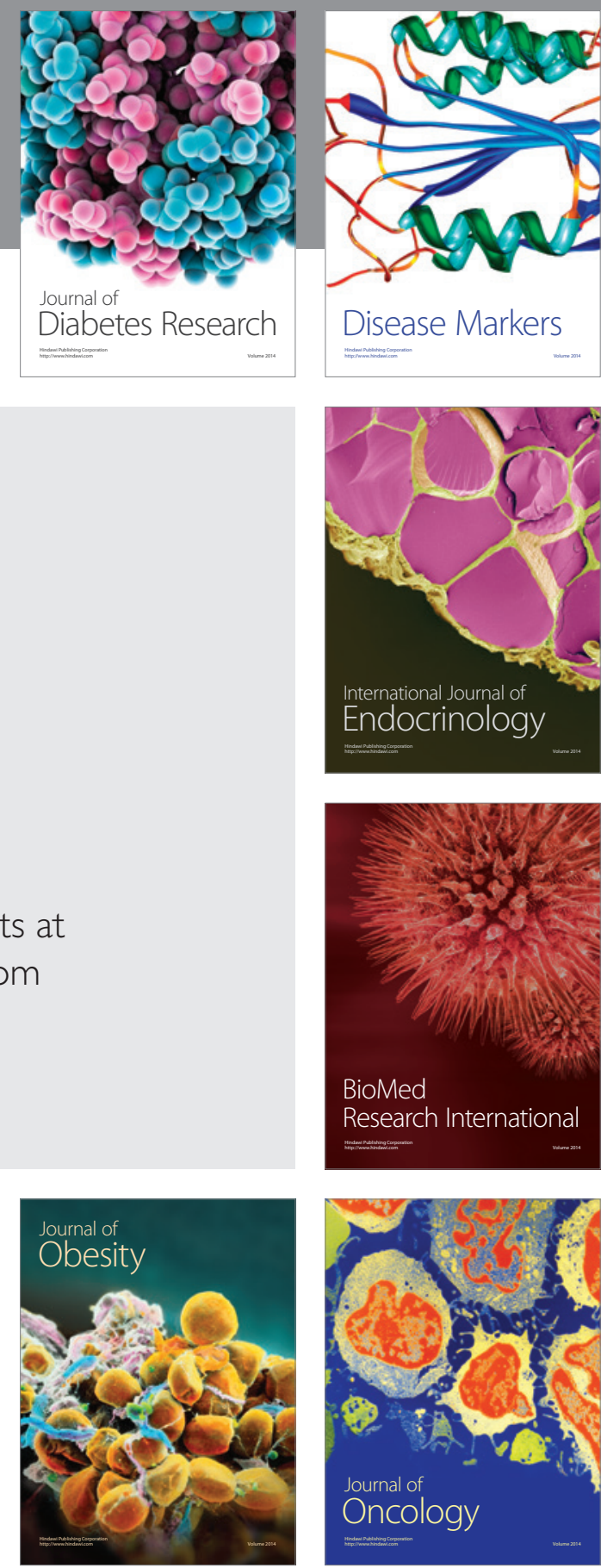

Disease Markers
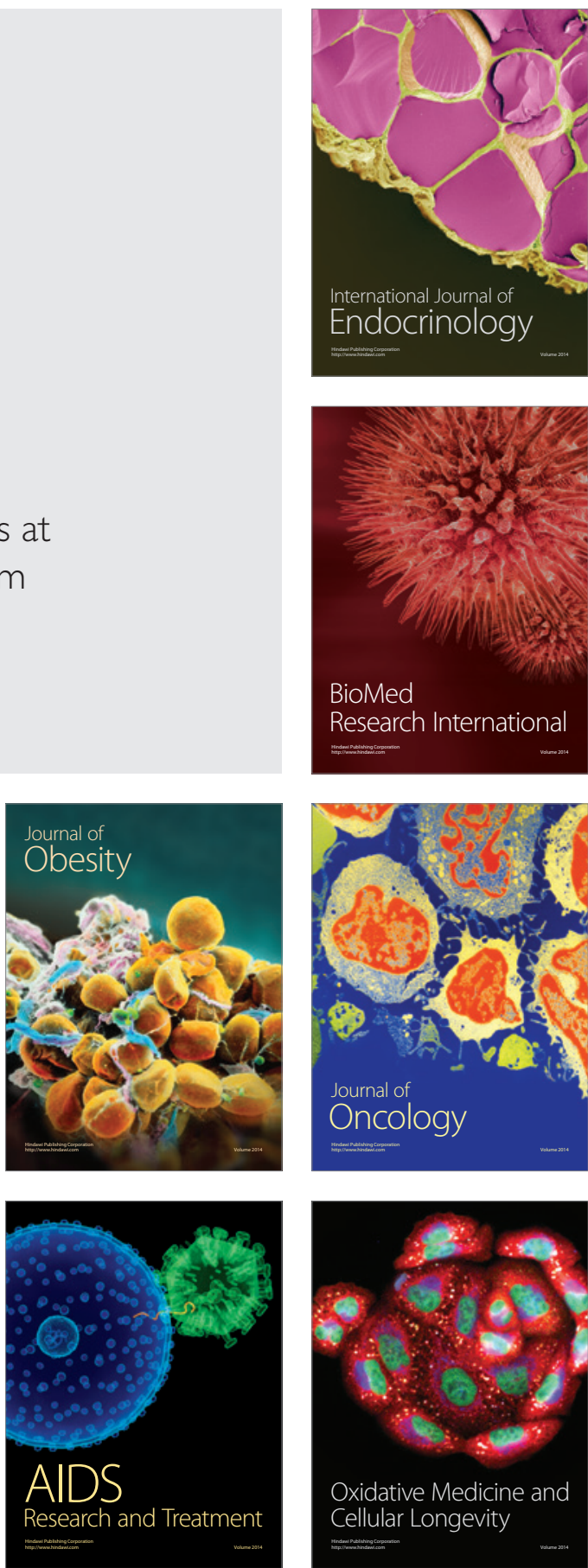